\title{
Power Enhancement by Vector Modulation Control of Inverter in Super Capacitor Integrated Hybrid System
}

\author{
Vijay Anand Bharti \\ M. Tech. Scholar \\ Lakshmi Narain College of Technology \\ Bhopal, India \\ er.vijayanandb@gmail.com
}

\author{
Rohit Gupta \\ Asst. Professor \\ Lakshmi Narain College of Technology \\ Bhopal, India \\ rohit.guptamtec@gmail.com
}

\begin{abstract}
For energy systems in remote and remote communities, an autonomous energy system based on renewable energy can be a particularly interesting and economically advantageous solution, since the expansion of the network is often impractical due to economic and technical constraints. In this research work, we designed a hybrid solar PV system with Wind energy system in as to enhance its output capacity before its integration with the grid. Also the system is integrated with a super capacitor model for handling the change in the power demand of the system. The inverter has been modeled with Vector modulation technique which has resulted in more smooth and better output result when used in combination with DC output voltage. It was concluded that magnitude of active power output is better from the system having inverter with vector modulation control as compared to the system having inverter with simple pulse modulation control. While calculating the RMS value of the active power it was found to be approximately $5000 \mathrm{VA}$ and less pulsating than that of power output from the inverter having Pulse Modulation Control. Also computational methodology of the proposed modulation technique is very easy and the technique can be applied to multilevel inverter with any number of levels.
\end{abstract}

\section{I.INTRODUCTION}

\section{Overview of Hybrid Power System}

Due to the rapid growth and challenges related to the production, distribution and use of energy, renewable energy technologies can play an important role in the future supply of electricity thanks to the increased awareness of environmental pollution. For energy systems in remote and remote communities, an autonomous energy system based on renewable energy can be a particularly interesting and economically advantageous solution, since the expansion of the network is often impractical due to economic and technical constraints. Diesel generators are most commonly used as autonomous power system applications in remote and isolated communities because of their reliability, economical installation, easy commissioning, compact power density and portability. The increase in fuel prices, however, makes them very expensive.

\section{Wind Energy Conversion System}

In the last decade, wind generation systems have intimate with tremendous growth and been recognized as an alternate environmentally-friendly and cost-efficient means of power generation. the foremost elements of a typical wind energy conversion system (WECS) include a turbine, generator and control systems. Fig. 1.4 shows a WECS. The generators conventionally employed in WECSs are the doubly-fed induction generator (DFIG), cage induction generator (IG), and synchronous generators (SG). the power electronics correspond to a consecutive convertor. The WECS are often connected to an oversized utility, a micro-grid (weak grid), or a complete load.

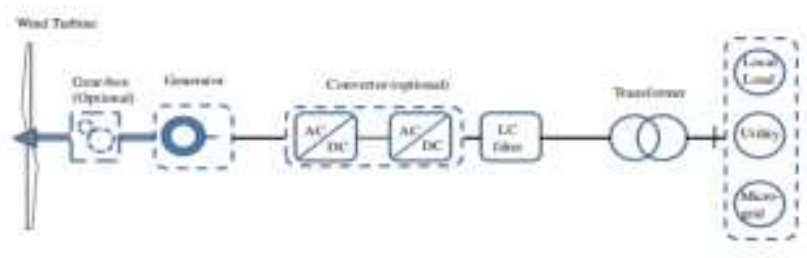

Figure 1 Wind energy conversion system

\section{DFIG- based WECS}

The DFIG is broadly utilized for variable-speed generation and is a standout amongst the most vital 
generators for wind-vitality applications. The DFIGbased WECS is appeared in Fig. 1.5. These days, the DFIG-based wind turbine represents about half of windenergy market share. For a normal DFIG, a consecutive power converter is associated with the rotor for a confined speed range of operation, commonly $30 \%$ of its rated value. In DFIG-based WECS, slip rings associate the machine-side converter to the rotor, and gearboxes are likewise required, since a multi-pole lowspeed DFIG isn't actually achievable.

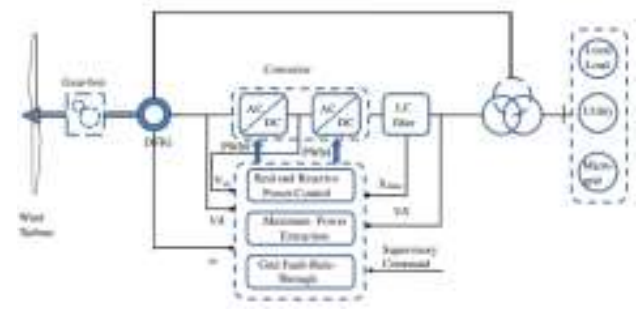

Figure 2: DFIG-based WECS

\section{SCIG-based WECS}

The squirrel-cage IG (SCIG) appeared in Fig. 1.6, is a prominent machine because of its mechanical straightforwardness and strong development. In contrast to the DFIG, no brushes are required for the machine's task. Minimal maintenance is important, aside from bearing oil. The SCIG was generally utilized in fixedspeed WECS (first Danish breeze turbines), and it is as yet utilized for variable-speed wind-energy age. The IG with a frequency converter is totally decoupled from the grid; consequently this framework has a total network association capacity.

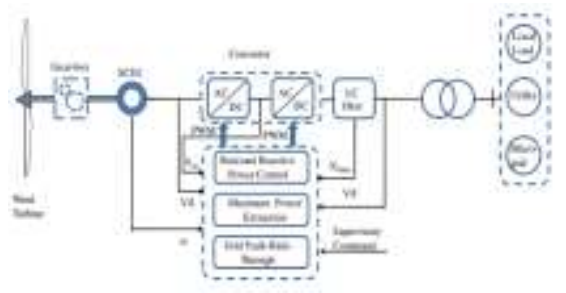

Figure 3. SCIG-based WECS

\section{II.LITERATURE REVIEW}

M. K. Hossain et al. [1] This paper proposes three nonlinear controllers, for example, fuzzy logic controller (FLC), static nonlinear controller (SNC), and adaptivenetwork-based fuzzy inference system (ANFIS)-based variable resistive-type fault current limiter (VR-FCL) to expand the transient security of an extensive scale mixture control framework comprising of a doubly fed induction generator (DFIG)- based breeze ranch, a photovoltaic (PV) plant, and a synchronous generator (SG). Suitable obstruction age of the VR-FCL amid a lattice blame to give better transient strength is the primary commitment of the work. The adequacy of the proposed control strategies in improving the transient security of the half and half power organize is confirmed by applying both adjusted and lopsided blames in one of the twofold circuit transmission lines associated with the framework. Recreation results demonstrate that the proposed FLC-, SNC-, or ANFIS-based VR-FCL are compelling in improving the transient dependability of the concentrated cross breed framework. Besides, all the proposed strategies show practically comparative execution. Consequently, any of the strategies can be picked for the transient steadiness upgrade of the crossover control framework.

H. M. Al- Masriet al. [2] this paper explores the practicality of wind-PV penetration into a current utility network framework for Ibrahimyya city in Jordan. Ibrahimyya is chosen since it appreciates both high yearly wind speed of $7.27 \mathrm{~m} / \mathrm{s}$ and high yearly sunlight based radiation of $6.05 \mathrm{kWh} / \mathrm{m} 2 /$ day. Two measuring strategies are introduced utilizing MATLAB and HOMER virtual products. Yet, a huge number of iterations have been completed in HOMER to get the worldwide selfgoverning measuring arrangement that is utilized for financial examination. Results demonstrate that 3 CS6X310 PV boards and 8 GE1.5sle-77 wind turbines are the ideal decision. A well-ordered examination of the proposed framework is exhibited. The net present cost (NPC) is 65,069,349thecostofenergy (COE) is $0.082 / \mathrm{kWh}$. An affectability investigation on loan fee, swelling rate, and wind control law example and fuel cost is actualized to survey the heartiness of the framework. The outcomes demonstrate the attainability to apply the proposed Hybrid Wind-PV framework for this city. A similar method can be connected anyplace.

Li Wang et al. [3] this paper assesses the dynamic stability of a hybrid wave and photovoltaic (PV) power generation framework coordinated into a distribution power network. Wave power-generation system (WPGS) is recreated by a linear permanent-magnet generator (LPMG) driven by an Archimedes wave swing (AWS). The yields of the WPGS and the PV framework are associated with a typical dc connect through a voltagesource converter (VSC) and a dc/dc help converter, separately. The normal dc connect is interfaced to the circulation control network through a voltage-source inverter (VSI). A super capacitor (SC) is used to smooth the created power conveyed to the dissemination control framework. This paper proposes a control plan to keep up stable activity of the examined framework while accomplishing most extreme power extractions for the wave framework and the PV framework. Both root-loci investigation of the framework eigenvalues under different working conditions and the time-space simulation results of the considered framework subject to 
unsettling influence conditions are exhibited to show and confirm the viability of the SC joined with the proposed control plot on power improvement of the concentrated hybrid wave and PV framework.

S.-Y. Lu et al. [4] this paper exhibits the power-quality estimation results of a photovoltaic (PV) framework associated with the distributed arrangement of Peng-Hu Power System, Taiwan. The examined PV framework with limit of $70.38 \mathrm{~kW}$ is associated with the distribution system of $380 \mathrm{~V}$ through thirteen DC/AC inverters that are situated at the best floor of one of the structures of National Peng-Hu University of Science and Technology, Peng-Hu. The deliberate information were recorded from September 25th to October first, 2013 for complete 7 days. The recorded outcomes incorporate three-stage voltages, flows, dynamic power, reactive power, power factor, frequency, current harmonics, voltage flickers, and voltage variations. It tends to be unmistakably seen from the deliberate outcomes that the power nature of the examined PV framework can meet the lattice code of Taiwan Power Company amid the measurement time frame.

\section{III.OBJECTIVE}

There are following objective are to be expected from the present work

-Designing of a hybrid solar PV system with Wind energy system in MATLAB/SIMULINK so as to enhance its output capacity before its integration with the grid. Also the system has to be integrated with a super capacitor model for handling the change in the power demand of the system.

-To design a suitable controller for the three leg Universal Bridge converter such that it produces better output results than the traditional pulse modulation technique.

-The controller has to be designed with vector modulation technique, simple in implementation and operation.

-Enhance the system reliability and efficiency by integrating it with the grid via a transformer with the desired grid voltage and frequency.

\section{IV.METHODOLOGY}

\section{PV Module Modeling}

PV cells have single working point where the estimations of the current (I) and voltage (V) of the cell result in a most extreme power output. These qualities compare to a specific opposition, which is equivalent to V/I. A straightforward identical circuit of PV cell is appeared The MPPT calculation has been utilized so as to obtain the operation of solar powered module at greatest power output. $\mathrm{P}$ and $\mathrm{O}$ system has been brought into utilization.

A cell series resistance ( Rs ) is connected in series with parallel combination of cell photocurrent ( $\mathrm{I}_{\mathrm{ph}}$ ), exponential diode ( D ), and shunt resistance $\left(\mathrm{R}_{\mathrm{sh}}\right)$, I pv and $\mathrm{Vpv}$ are the cells current and voltage respectively. It can be expressed as

$I_{p v}=I_{p h}-I_{s}\left(e^{q\left(V_{p v}+I_{p v} * R_{S}\right) / n K T}-1\right)-\left(V_{p v}+I_{p v} * R_{s}\right) / R_{s h}$

Where:

I ph - Solar-induced current

Is - Diode saturation current

$q$ - Electron charge (1.6e-19C)

$K$ - Boltzmann constant $(1.38 \mathrm{e}-23 \mathrm{~J} / \mathrm{K})$

$n$ - Ideality factor $(1 \sim 2)$

$T$ - Temperature $0 \mathrm{~K}$

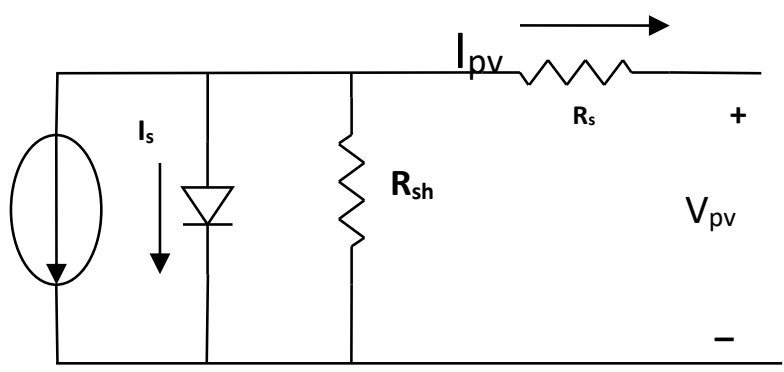

Figure 4: Equivalent circuit of solar pv cell

The solar induced current of the solar PV cell depends on the solar irradiation level and the working temperature can be expressed as:

$I_{p h}=I_{s c}-k_{i}\left(T_{c}-T_{r}\right) * \frac{I_{r}}{1000}$

Where:

Isc Short-circuit current of cell at STC

ki Cell short-circuit current/temperature coefficient $(\mathrm{A} / \mathrm{K})$

Ir Irradiance in $\mathrm{w} / \mathrm{m}$

2

$\operatorname{Tc}, \operatorname{Tr}$ Cell working and reference temperature at STC

A PV cell has an exponential relationship between current and voltage and the maximum power point (MPP) occur at the knee of the curve as shown in the Fig 7. 


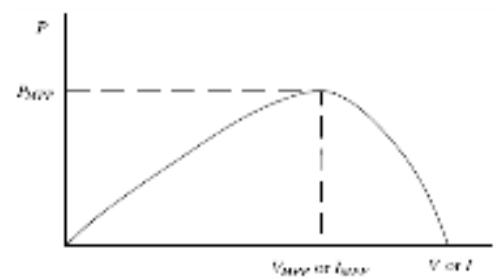

Figure 5: Characteristic PV array power curve

The P\&O calculation will follow the most maximum power to supply the DCMGs framework. The assumptions for model derivation are that the perfect current source can be displayed as the PVs behaviour. Likewise, all power converters are worked under the continuous conduction mode (CCM) and the harmonics are additionally overlooked.

\section{Wind Energy System Modeling}

Model of wind turbine with PMSG Wind turbines cannot fully capture wind energy. The components of wind turbine have been modelled by the following equations [8$10]$.

Output aerodynamic power of the wind-turbine is expressed as:

$P_{\text {Turbine }}=\frac{1}{2} \rho A C_{p}(\lambda, \beta) v^{3}$

where, $\rho$ is the air density (typically $1.225 \mathrm{~kg} / \mathrm{m} 3$ ), $A$ is the area swept by the rotor blades (in $\mathrm{m} 2$ ), $C P$ is the coefficient of power conversion and $v$ is the wind speed (in $\mathrm{m} / \mathrm{s}$ ).

The tip-speed ratio is defined as:

$\lambda=\frac{\omega_{m} R}{v}$

where $\omega_{m}$ and $R$ are the rotor angular velocity (in $\mathrm{rad} / \mathrm{sec}$ ) and rotor radium (in $\mathrm{m}$ ), respectively.

The wind turbine mechanical torque output $m T$ given as:

$T_{m}=\frac{1}{2} \rho A C_{p}(\lambda, \beta) v^{3} \frac{1}{\omega_{m}}$

The power coefficient is a nonlinear function of the tipspeed ratio $\lambda$ and the blade pitch angle $\beta$ (in degrees).

Then Power output is given by

$P_{\text {Turbine }}=\frac{1}{2} \rho A C_{p_{\max }} v^{3}$

A generic equation is utilized to display the power coefficient $\mathrm{CP}$ dependent on the modeling turbine attributes portrayed in [2], [7-9] and [11] as:
$C_{p}=\frac{1}{2}\left(\frac{116}{\lambda_{i}}-0.4 \beta-5\right) e^{-\left(\frac{21}{\lambda_{i}}\right)}$

For each wind speed, there exists a particular point in the wind generator control characteristic, MPPT, where the output power is boosted. Along these lines, the control of the WECS load results in a variable-speed activity of the turbine rotor, so the greatest power is taken constantly from the wind (MPPT control).

\section{Modeling Of Super Capacitor}

It is important that under the varieties of wind speed and solar irradiance, the powers fed to the normal dc connect from the WTG and PV cluster may be significantly vacillated. So as to smooth out the power changes and, thus, stifle them from exchanging to the $\mathrm{AC}$ grid, the intensity of the SC should be managed to make up for the power variations.

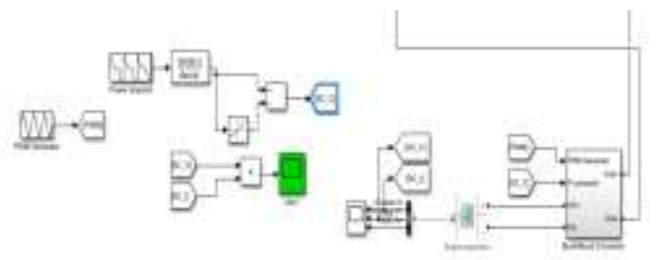

\section{Figure 6: MATLAB/SIMULINK Model of Super Capacitor}

To achieve this objective, the reference value SC_C of the power control loop can be controlled by utilizing the averaging system as delineated in Fig.

The supercapacitor is associated with a Buck/Boost converter. Intensity of the capacitor is restricted by a rate limiter square, along these lines the transient power is provided to the DC bus by the supercapacitor.

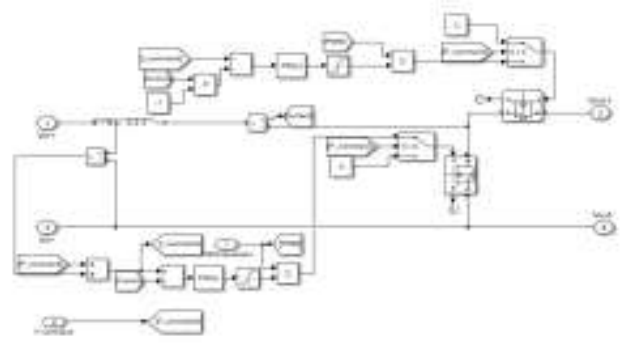

Figure 7: Buck Boost Converter Control in MATLAB

The flow of energy from or to buffer must be controlled according to requirements of power management. The converter operates either in Boost mode during energy delivering from buffer to dc line or in Buck during buffer charging (8a). Buck mode has a output voltage U Uut is lesser than the voltage input $\mathrm{U}_{\text {IN }}$ and output voltage can be calculated by following formula:

$U_{\text {OUT }}=D \cdot U_{I N}$ 
where $\mathrm{D}=\mathrm{t}_{\mathrm{ON}} / \mathrm{T}$ duty cycle.

In boost mode both voltage ( $\mathrm{U}_{\mathrm{IN}}$ and $\mathrm{U}_{\mathrm{OUT}}$ ) are variable and the output voltage must be controlled to achieve constant voltage. Output voltage is calculated according to follow formula:

$U_{\text {OUT }}=\frac{U_{I N}}{1-D}$

\section{Vector Modulation}

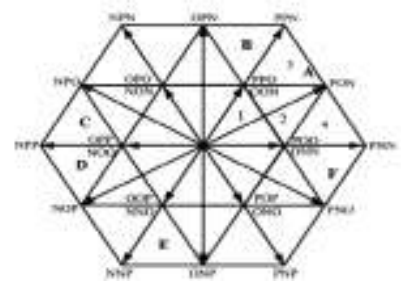

Figure 8: Space-vector diagram of the three-level converter

Assuming the instantaneous voltage value of three-phase sine wave is respectively:

$\mathrm{U}_{\mathrm{a}}=\mathrm{V}_{\mathrm{m}} \operatorname{Sin}(\mathrm{wt})$

$\mathrm{U}_{\mathrm{b}}=\mathrm{V}_{\mathrm{m}} \operatorname{Sin}(\mathrm{wt}-2 \pi / 3)$

$\mathrm{U}_{\mathrm{c}}=\mathrm{V}_{\mathrm{m}} \operatorname{Sin}(\mathrm{wt}+2 \pi / 3)$

The magnitude and angle of the rotating vector can be found as below:

$\left[\begin{array}{l}V_{\alpha} \\ V_{\beta}\end{array}\right]=\frac{2}{3}\left[\begin{array}{ccc}1 & -1 / 2 & -1 / 2 \\ 0 & \sqrt{3} / 2 & -\sqrt{3} / 2\end{array}\right]\left[\begin{array}{l}U_{a} \\ U_{b} \\ U_{c}\end{array}\right]$

$\overrightarrow{V_{\text {ref }}}=V_{\alpha}+j V_{\beta}=\frac{2}{3}\left(U_{a}+a U_{b}+a^{2} U_{c}\right)$

Where,

$\mathrm{a}=e^{j 2 \pi / 3}$

$\left|\overrightarrow{V_{\text {ref }}}\right|=\sqrt{V_{\alpha}^{2}+V_{\beta}^{2}}, \theta=\tan ^{-1}\left(V_{\beta} / V_{\alpha}\right)$

If $\theta$ is between $0^{\circ} \leq \theta<60^{\circ}$, then Vref will be in Sector A.

If $\theta$ is between $60^{\circ} \leq \theta<120^{\circ}$, then Vref will be in Sector B.

If $\theta$ is between $120^{\circ} \leq \theta<180^{\circ}$, then Vref will be in Sector C.

If $\theta$ is between $180^{\circ} \leq \theta<240^{\circ}$, then Vref will be Sector D.

If $\theta$ is between $240^{\circ} \leq \theta<300^{\circ}$, then Vref will be Sector E.

If $\theta$ is between $300^{\circ} \leq \theta<360^{\circ}$, then Vref will be Sector F.

The fundamental thought of the improved calculation is the manner by which to accomplish the Calculation Flow dependent on one sector rather than six as exhibited in Fig. 6, just by realizing the connections in Dwell Time computations and arrangement for switches between the first sector and the others as clarified beneath::

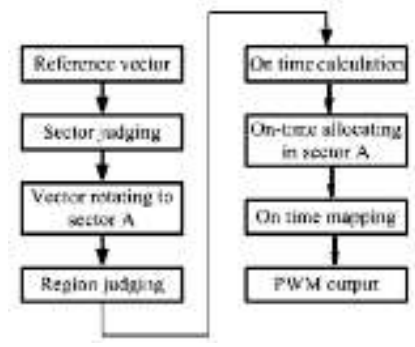

Figure 9: Calculation flow for the three-level SVPWM Simplified calculation

Suppose reference vector A stays in region 2 of sector A, while reference vector $\mathrm{B}$ is obtained by rotating vector $\mathrm{A}$ counterclockwise by $60^{\circ}$ as shown in Fig .4.7

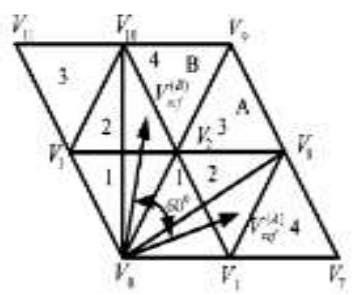

Figure 10. Two vectors with 600 shifting in the sector $A$ and $B$.

So the reference vector $V_{\text {ref }}$ can be expressed in the following form.

$V_{r e f}^{B}=V_{r \theta f}^{A} * e^{\frac{j \pi}{3}}=2 / 3\left(-U_{b}-U_{c} e^{\frac{j 2 \pi}{s}}-U_{a} e^{\frac{-j 2 \pi}{s}}\right)$

And when the reference vector is in the other sectors, it will be rotated to sector A by $n \pi / 3$ where $(n=1,2,3,4,5)$. The corresponding reference vector in other sectors can be constructed as given in Table 5 .

Table 4.1. Relationships Of Voltages Constructing The Reference Vectors In Six Sectors.

\begin{tabular}{|l|l|l|l|}
\hline Sectors & Phase Voltage A & Phase Voltage B & Phase Voltage C \\
\hline A & $\mathrm{U}_{\mathrm{a}}$ & $\mathrm{U}_{\mathrm{b}}$ & $\mathrm{U}_{\mathrm{c}}$ \\
\hline B & $-\mathrm{U}_{\mathrm{b}}$ & $-\mathrm{U}_{\mathrm{c}}$ & $-\mathrm{U}_{\mathrm{a}}$ \\
\hline C & $\mathrm{U}_{\mathrm{c}}$ & $\mathrm{U}_{\mathrm{a}}$ & $\mathrm{U}_{\mathrm{b}}$ \\
\hline D & $-\mathrm{U}_{\mathrm{a}}$ & $-\mathrm{U}_{\mathrm{b}}$ & $-\mathrm{U}_{\mathrm{c}}$ \\
\hline E & $\mathrm{U}_{\mathrm{b}}$ & $\mathrm{U}_{\mathrm{c}}$ & $\mathrm{U}_{\mathrm{a}}$ \\
\hline F & $-\mathrm{U}_{\mathrm{c}}$ & $-\mathrm{U}_{\mathrm{a}}$ & $-\mathrm{U}_{\mathrm{b}}$ \\
\hline
\end{tabular}

V.RESULTS

The examination of the model has been done in MATLAB/SIMULINK condition. MATLAB consolidates a work area condition tuned for iterative investigation and design process with a programming language that communicates matrix and array science 
straightforwardly. It enables graphical programming to structure your framework in a simulation environment.

In this work, Solar and wind energy control frameworks has been displayed together to upgrade the reliability of the total distributed generation [DG] framework. Additionally, this design enables the two sources to supply the load independently or at the same time contingent upon the accessibility of the vitality sources

\section{Solar Powered Cell Model}

The solar system consists of an adaptive MPPT algorithm with perturb and observe [P \& O] has been implemented. Figure 1 and 2 shows the MPPT voltage and MPPT power when the model is simulated for 2 seconds. The output of solar module is provided as input to DC-DC boost converter which is an average valued buck converter. 'Duty cycle' of this converter consist duty cycle of internal IGBT device. The super capacitor benefits the system by storing / supplying excessive power to DC grid during low/ heavy load conditions.

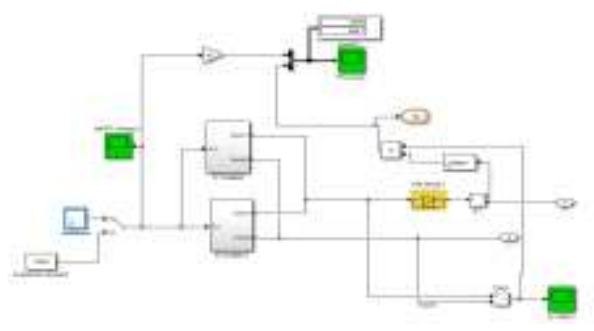

Figure 11: Modeled Solar System

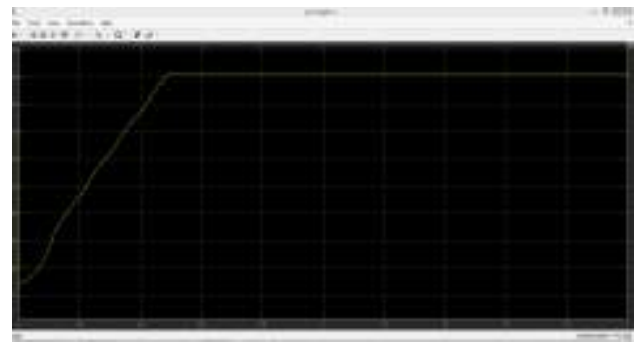

Figure 12: Voltage Output from the solar system

\section{Wind system Model}

Permanent magnet synchronous generator has been modeled having stator phase resistance 0.425 ohms, armature inductance $0.000395 \mathrm{H}$, and Pole Pairs 5. The base input torque is taken to be $152.89 \mathrm{Nm}$. The table below shows the various system parameters that has been modeled in wind energy system using MATLAB/SIMULINK

\begin{tabular}{|l|l|}
\hline \multicolumn{2}{|l|}{ Table 5.1 : Wind Energy System Parameters } \\
\hline Wind Turbine Model \\
\hline $\begin{array}{l}\text { Nominal Mechanical } \\
\text { Output Power (W) }\end{array}$ & $8.5 \mathrm{e} 3$ \\
\hline Base Wind Speed (m/s) & 12 \\
\hline $\begin{array}{l}\text { Maximum power at Base } \\
\text { Wind Speed (p.u) }\end{array}$ & 0.8 \\
\hline $\begin{array}{l}\text { Base Rotational Speed } \\
\text { (p.u) }\end{array}$ & 1 \\
\hline Permanent Magnet Synchronous Machine \\
\hline $\begin{array}{l}\text { Stator Phase Resistance } \mathrm{R}_{\mathrm{s}} \\
\text { (ohms) }\end{array}$ & 0.425 \\
\hline Armature Inductance $(\mathrm{H})$ & 0.000395 \\
\hline Flux Linkage & 0.433 \\
\hline Pole Pairs & 5 \\
\hline
\end{tabular}

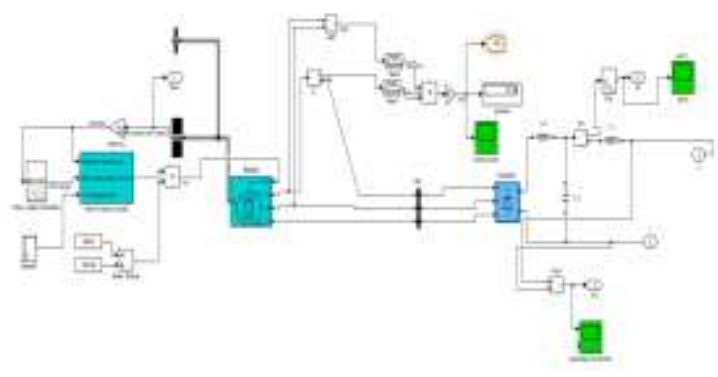

Figure 13: Modeled Wind System

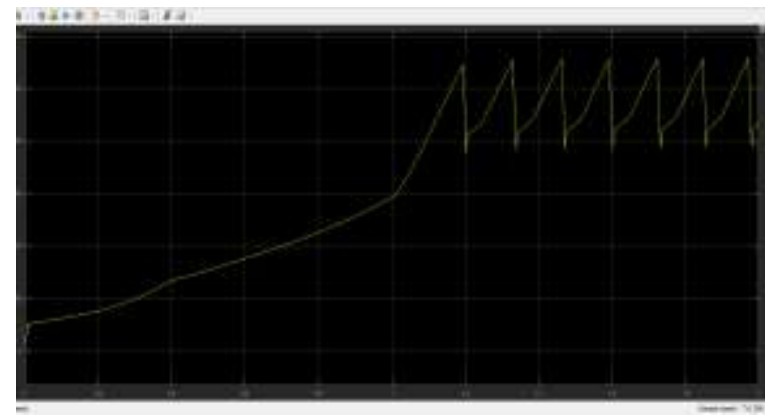

Figure 14: Voltage Output from the wind energy system

Outputs From The Inverter Modeling

Case 1: System Modeled With Pulse Modulation: 


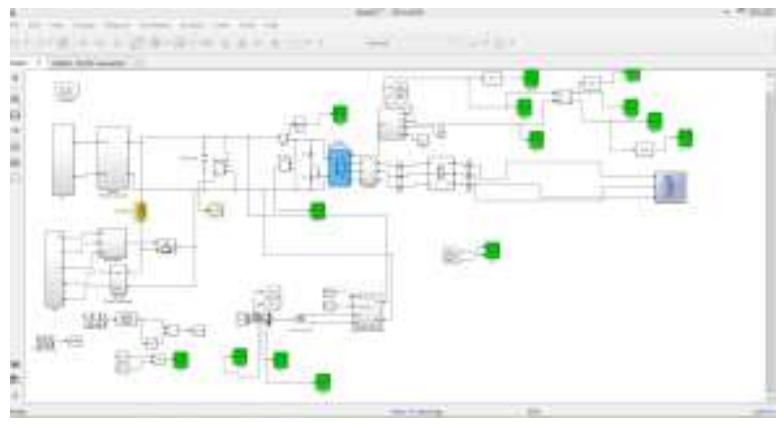

Figure 15: System Modeled With Pulse Modulation

The voltage and current outputs photo at a bus is taken as the reference for generating pulses. then their active and reactive power have been calculated to be fed into a PI controller that is connected to a pulse width modulation generator. Pulse width modulation generator will in turn generate pulses for the four leg modeled IGBT converter. proportional gain $\mathrm{K}_{\mathrm{p}}$ of the PI controller is kept to be 0.1 and the integral gain $\mathrm{K}_{\mathrm{i}}$ is kept to be 1 . The snubber resistance of the inverter is kept to be $5000 \mathrm{ohms}$.

The input DC voltage to the inverter which is being modeled with pulse modulation has been shown in the figure below and is coming approximately to be 800 volts

The three phase output voltage and current waveform of the inverter has been shown and it has been found that there is considerable amount of distortion in the voltage output. The RMS value of active and reactive power has also been detected

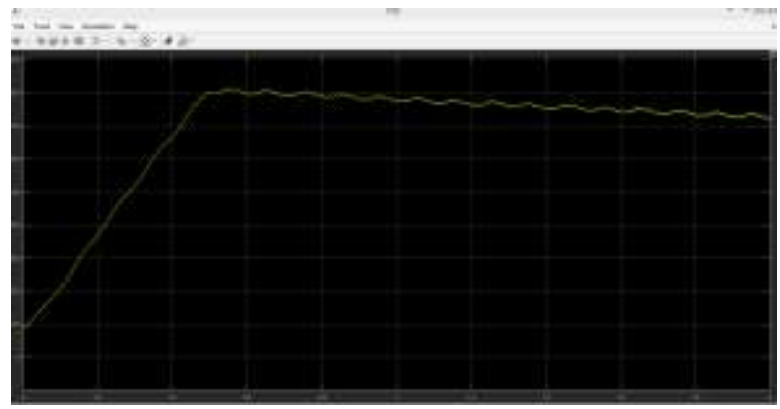

Figure 16: Input DC voltage to the inverter

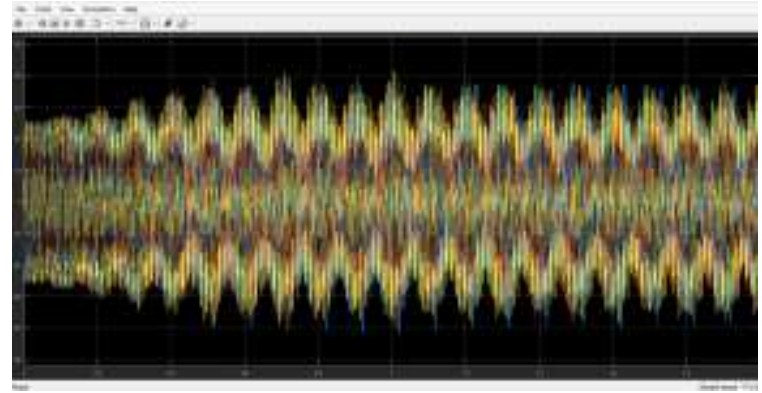

Figure 17:Voltage Output from the inverter with Pulse Modulation

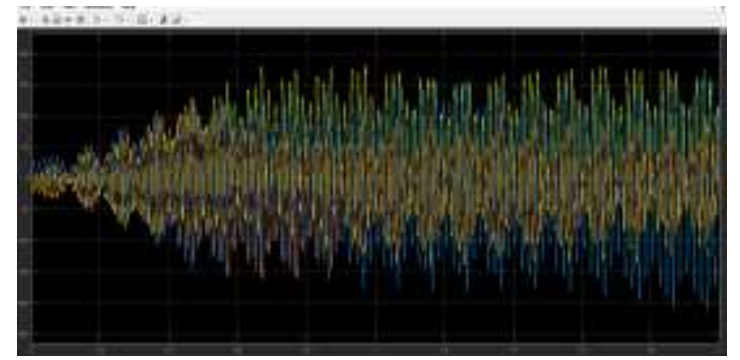

Figure 18: Current Output from the inverter with Pulse Modulation

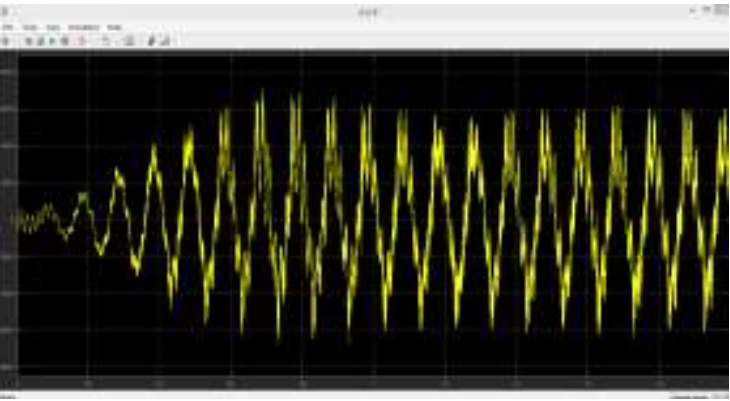

Figure 19: Active Power Output from the inverter with Pulse Modulation

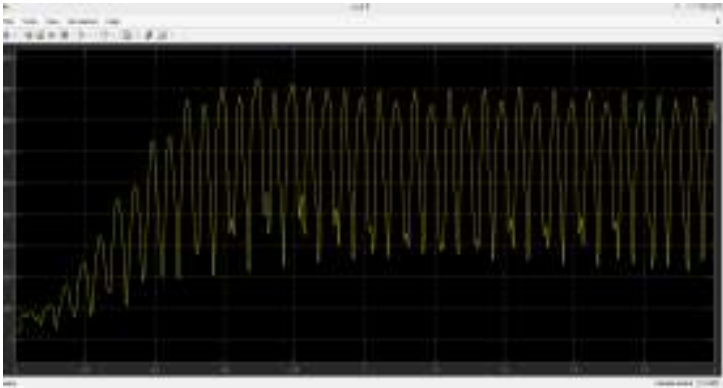

Figure 20: RMS value of active Power Output from the inverter with Pulse Modulation

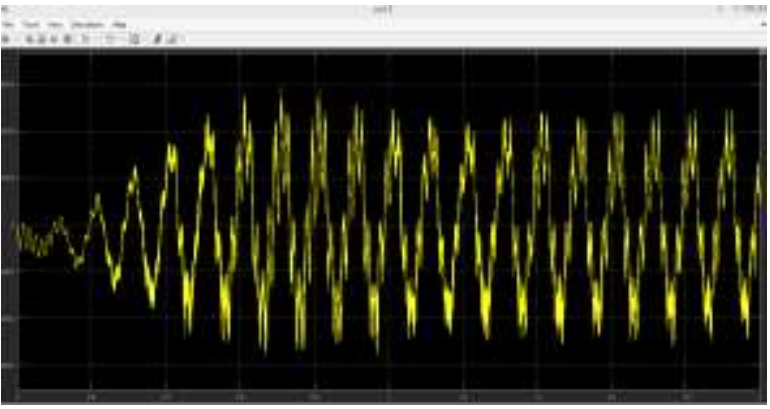

Figure 21: Reactive Power Output from the inverter with Pulse Modulation 


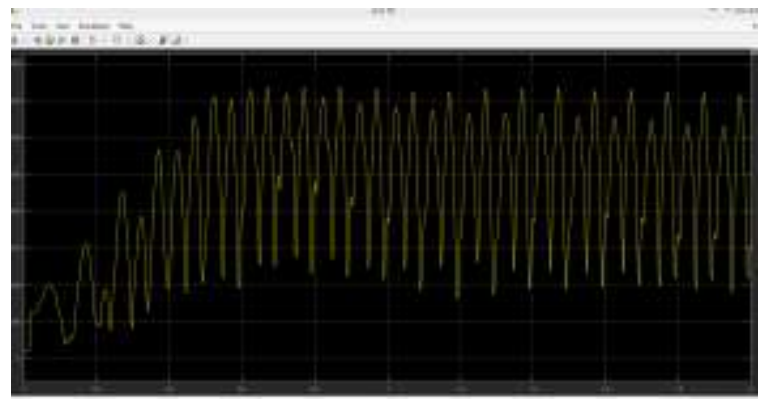

Figure 22: RMS value of Reactive Power Output from the inverter with Pulse Modulation

\section{Case 2: System Modeled With Vector Modulation}

Solar and wind hybrid energy system with super capacitor has been modeled using space vector modulation to generate 6 pulses for the three bridge inverter.

The input DC voltage to the inverter which is being modeled with pulse modulation has been shown in the figure below and is coming approximately to be 800 volts,. This voltage when fed to the inverter is more stable as compared to the DC voltage in case of pulse width modulation control.

The three phase output voltage and current waveform of the inverter has been shown and it has been found that there is very less amount of distortion in the voltage output and the waveform is quite smooth and continuous. The RMS value of active and reactive power has also been detected for further comparative analysis of the results.

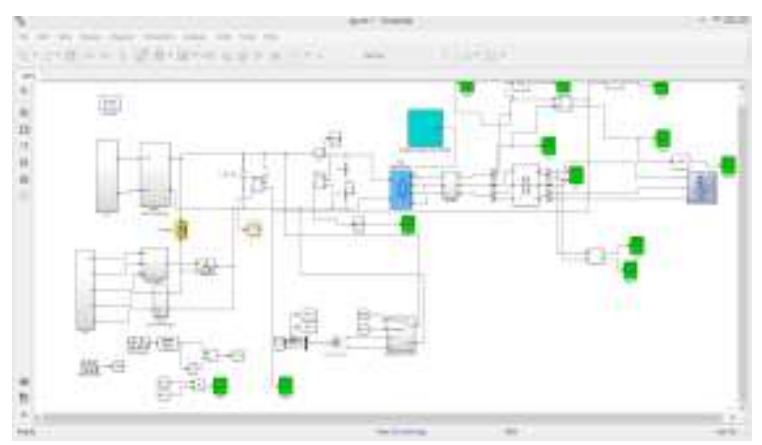

Figure 23: System Modeled With Vector Modulation

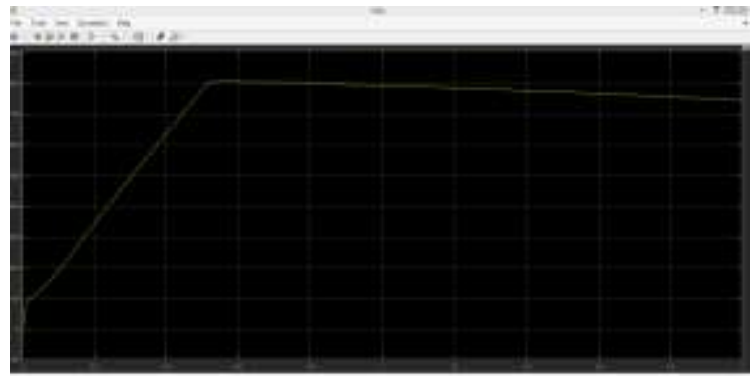

Figure 24: DC voltage input to the inverter

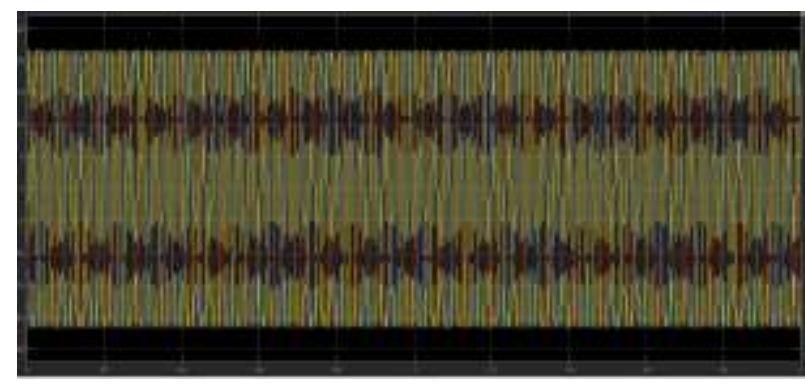

Figure 25: Voltage Output from the inverter with Vector Modulation

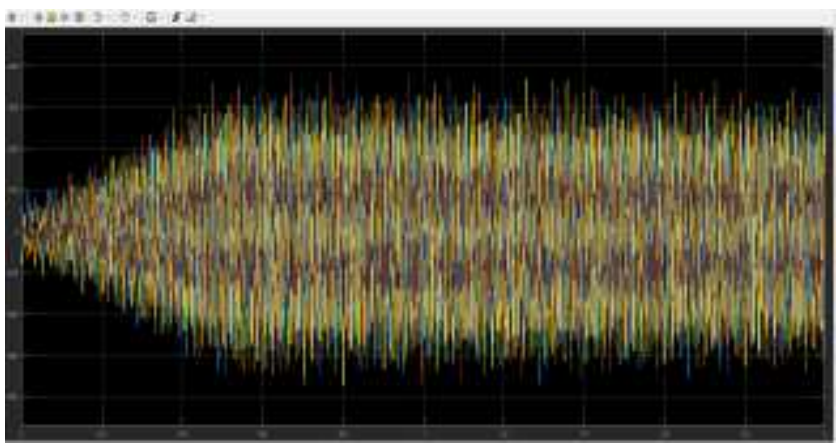

Figure 26: Current Output from the inverter with Vector Modulation

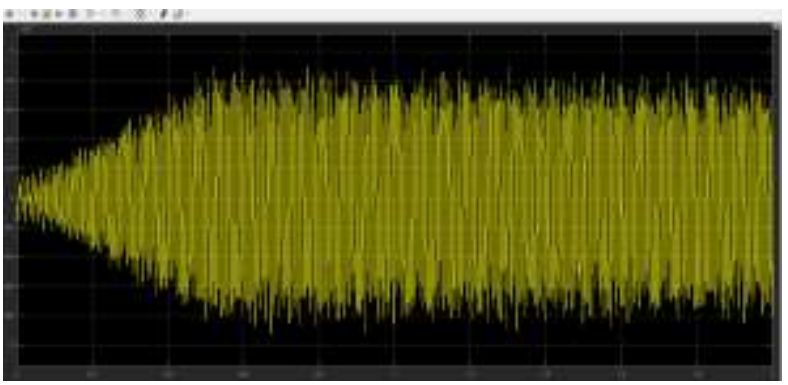

Figure 27: Active Power Output from the inverter with Vector Modulation

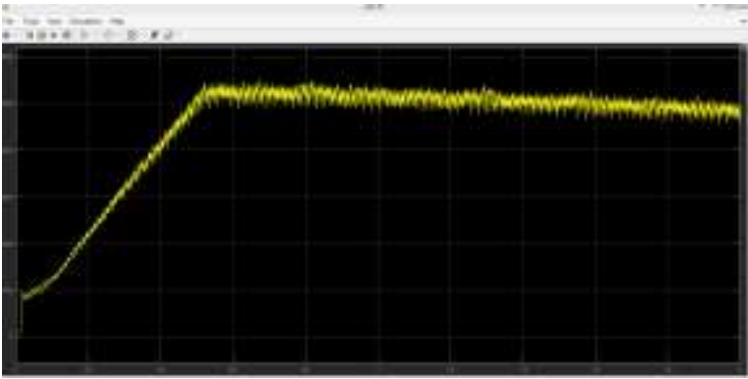

Figure 28: RMS value of Active Power Output from the inverter with Vector Modulation 


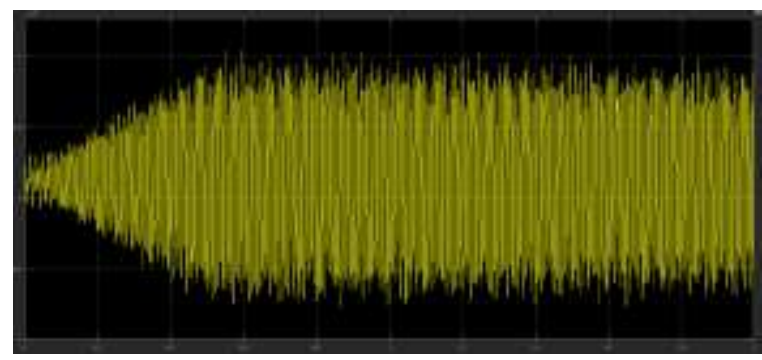

Figure 29: Reactive Power Output from the inverter with Vector Modulation

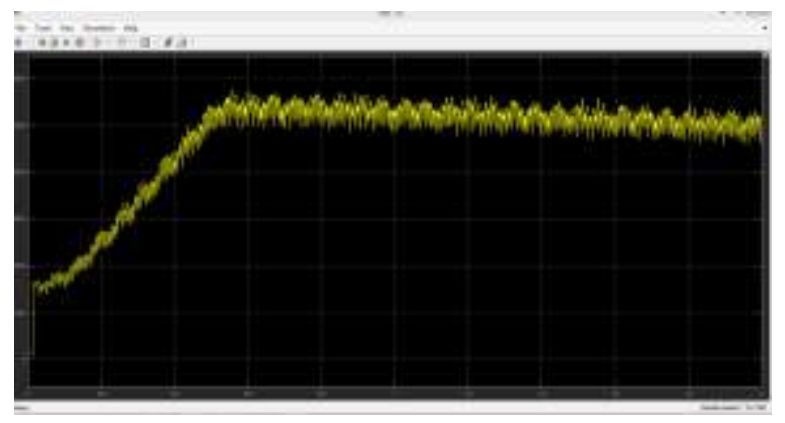

Figure 30: RMS Value of Reactive Power Output from the inverter with Vector Modulation

\section{Outputs Being Fed To The Grid}

The grid energy systems has been model having two synchronous machine with their respective regulator's and exciters. Also there are two voltage sources which Phase to phase voltage of 230 kilovolts and frequency 50 Hertz.

\begin{tabular}{|l|l|}
\hline \multicolumn{2}{|l|}{ Table 5.2 : System Parameters of the grid } \\
\hline Synchronous machine \\
\hline Number of machines & 2 \\
\hline Nominal Power & $400 \mathrm{MVA}$ \\
\hline Line to Line voltage & $20 \mathrm{KV}$ \\
\hline Frequency & $50 \mathrm{~Hz}$ \\
\hline Transformers & $20 \mathrm{KV}$ \\
\hline Winding 1 voltage & $230 \mathrm{KV}$ \\
\hline Winding 2 voltage & $400 \mathrm{MVA}$ \\
\hline Nominal power & $50 \mathrm{Hertz}$ \\
\hline Frequency & $230 \mathrm{KV}$ \\
\hline Three Phase Voltage source \\
\hline Phase to phase voltage & $16.58 \times 10-3 \mathrm{H}$ \\
\hline Source inductance & 0.0001 ohms \\
\hline Source resistance & \\
\hline
\end{tabular}


As shown in above graphs the magnitude of active power output is better from the system having inverter with vector modulation control as compared to the system having inverter with simple pulse modulation control.

Also it can be concluded that The RMS value of the active power in inverter having pulse modulation is highly pulsating between 1000 and $4000 \mathrm{VA}$. Whereas in case of inverter having vector modulation control The RMS value is approximately DC signal at 5000 volt ampere and less pulsating then the other graph.

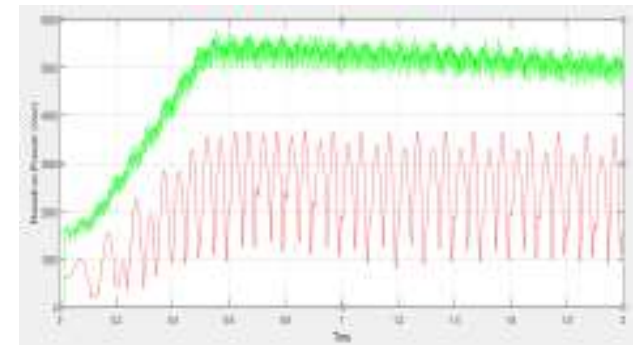

Figure 35: Comparison of RMS value of Reactive Power Output with vector modulation and without vector modulation

Similarly The RMS value of the reactive power in system having vector modulation is better as compared to The RMS value of reactive power in system having pulse modulation. It can also be seen that the variation in the reactive power is more with pulse modulation control as compared to vector modulation.

Hence it can be concluded that if the system is modeled with the inverter having that the modulation control the output waveform have more stable output which is also better in magnitude as compared to simple pulse modulation control.

Hence using vector modulation control while modelling hybrid solar wind energy system along with supercapacitor control which is finally integrated with the grid is a better option

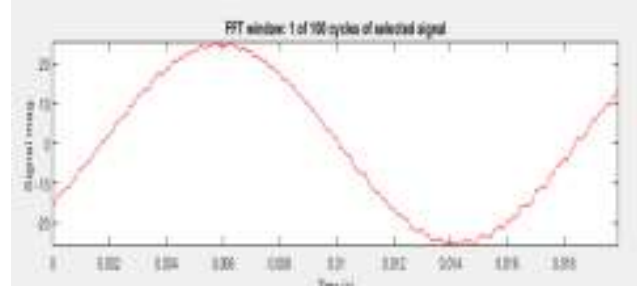

Figure 36: FFT analysis of Voltage Output from the inverter with Pulse Modulation

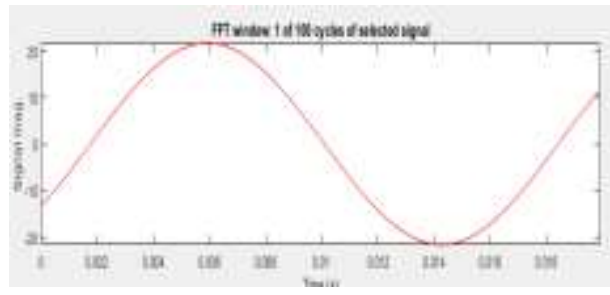

Figure 37: FFT Analysis of the voltage output from the inverter with vector modulation

In order to see the distortion in one cycle of the voltage waveform output from the inverter FFT analysis of the voltage output is done. It can be concluded from the above FFT Windows that the voltage output from the inverter with pulse modulation is having more distortion as compared to the voltage output from the inverter having vector modulation control. Again it is concluded from the output waveform of the inverter that vector modulation is better control than simple pulse with modulation

\section{CONCLUSION}

This work provides a comprehensive design and implementation of three-level Universal Bridge inverter in a hybrid PV Wind Energy system coupled with a super capacitor model. The Inverter has been provided with proposed Space Vector Modulation Technique while integrating it with the grid.

The basic idea about SVPWM for three-legged voltage source inverter was discussed in detail. It is illustrated how the voltage space vectors are defined in a threedimensional (3-D)plane for a cascaded H-bridge multilevel inverter. The comparative analysis of the proposed techniwue in a hybrid super capacitor based model shows its effectiveness and an efficient choice for operation of grid integrated inverters

The following main conclusive points were drawn during the analysis of the system in the MATLAB/SIMULINK environment.

-The magnitude of active power output is better from the system having inverter with vector modulation control as compared to the system having inverter with simple pulse modulation control. While calculating the RMS value of the active power it was found to be approximately 5000 VA and less pulsating than that of power output from the inverter having Pulse Modulation Control.

-Also the RMS value of the reactive power in system having vector modulation is better as compared to The RMS value of reactive power in system having pulse modulation in magnitude as well as in stability.

-The voltage output of the system from the is being fed to the inverter for DC to AC conversion. The FFT analysis of the output voltage waveform confirms that the voltage 
output from the inverter having proposed Space Vector Modulation Technique is less distorted than that of Pulse Modulation Technique.

-The computational methodology of the proposed modulation technique is very easy and the technique can be applied to multilevel inverter with any number of levels.

The system performance has been enhanced by further integrating the system with Super Capacitor Model that would compensate for the changes in the power demand of the system.

\section{REFERENCES}

[1]M. K. Hossain and M. H. Ali, "Transient stability augmentation of PV/DFIG/SG-based hybrid power system by nonlinear control-based variable resistive FCL," IEEE Trans. Sustainable Energy, Vol. 6, No. 4, pp. $1638-1649$, Oct. 2015.

[2]H. M. Al- Masri and M. Ehsani, "Feasibility investigation of a hybrid on -grid wind photovoltaic retrofitting system," IEEE Trans. Industry Applications, Vol. 52, No. 3, pp. 1979-1988, May/Jun. 2016.

[3]Li Wang and Quang-Son Vo "Dynamic Stability Analysis of a Hybrid Wave and Photovoltaic Power Generation System Integrated Into a Distribution Power Grid" January 2016 DOI: 10.1109/TSTE.2016.2602370

[4]S.-Y. Lu and S.-C. Ke "Analysis of measured powerquality results of a PV system connected to Peng-Hu power system" December 2014 DOI: 10.1109/IAS.2014.6978484

[5]Li Wang and S.-Y. Lu "A preliminary study on total energy-density variations of a Buddhist temple in Taiwan through long-term field measurements of electric-field strength" December 2014 DOI: 10.1109/IAS.2014.6978485

[6]Hussein M. Al-Masri and Mehrdad Ehsani "Feasibility Investigation of a Hybrid On-Grid Wind Photovoltaic Retrofitting System" IEEE Transactions on Industry Applications 52(3):1-1 • January 2015 DOI: 10.1109/TIA.2015.2513385

[7]Sheng-yen Lu and Che-Hao Chang "Evaluation of Measured Power-Quality Results of a Wind Farm Connected to Taiwan Power System" January 2015 DOI: 10.1109/TIA.2015.2463766

[8]Anton Prokhorov and S.-Y. Lu "Integration of WindPower and Wave-Power Generation Systems Using a
DC Micro Grid" July 2015 DOI: 10.1109/TIA.2014.2367102 